\title{
The sum of small pieces
}

\author{
Christoph Haller, MD
}

\footnotetext{
From the Department of Cardiovascular Surgery, The Labatt Family Heart Centre, The Hospital for Sick Children, University of Toronto, Toronto, Ontario, Canada.

Disclosures: Author has nothing to disclose with regard to commercial support.

Received for publication Sept 11, 2017; accepted for publication Sept 15, 2017; available ahead of print Oct 15 , 2017.

Address for reprints: Christoph Haller, MD, Division of Cardiovascular Surgery, The Hospital for Sick Children,

555 University Ave, Toronto, Ontario, Canada M5G 1X8 (E-mail: christoph.haller@sickkids.ca).

J Thorac Cardiovasc Surg 2018; 155:e57

$0022-5223 / \$ 36.00$

Copyright (C) 2017 by The American Association for Thoracic Surgery

https://doi.org/10.1016/j.jtcvs.2017.09.076
}

Aorta-right ventricular tunnel is a very rarely encountered pathology, and clinical information is limited to case reports and series. ${ }^{1,2}$ Patients with the various types of aortocameral connections usually need therapeutic intervention, either by catheter occlusion or by surgical closure, ${ }^{2}$ although a conservative approach has been suggested in select cases. ${ }^{3}$ Case reports are therefore especially important to build a stronger body of knowledge of a disease that cannot be analyzed in large studies. In this issue of the Journal, Dellis and colleagues ${ }^{4}$ report the interesting case of a 38-year-old woman who presented with atypical chest pain, palpitations, and signs of heart failure and ultimately had an aorta-right atrial tunnel diagnosed. Surgical closure of the tunnel was performed without complications, and the patient recovered quickly.

In the presented case of aorta-right atrial tunnel, much more could be learned if more information on the anatomic and physiologic features, the decision-making process, and the surgical repair itself had been provided. The images indicate a significant enlargement of the left coronary sinus, and it must be assumed that this mandated surgical repair. Dellis and colleagues, ${ }^{4}$ however, describe closure of the aortic ostium of the tunnel with polypropylene suture only. If the suggested mechanism of the tunnel was structural weakness of the sinus wall, did it appear to be structurally abnormal, and was the surgical technique altered to prevent recurrence of an aneurysm? The aortic origin of the tunnel arose centrally from the left sinus of Valsalva. The anatomic description and the computed tomography give the impression that the tunnel must have originated close to the coronary ostium, suggesting that the surgical repair must have taken the coronary's course and ostial position into account to avoid coronary distortion. The additional presence of a patent ductus arteriosus, which is casually mentioned, raises further questions regarding long-standing pulmonary overcirculation that may have contributed to the patient's symptoms. In this scenario, magnetic resonance imaging for further assessment of shunt volume would be of great pathophysiological interest.

The multitude of cardiovascular diseases encountered in clinical practice, both congenital and acquired, is one of the

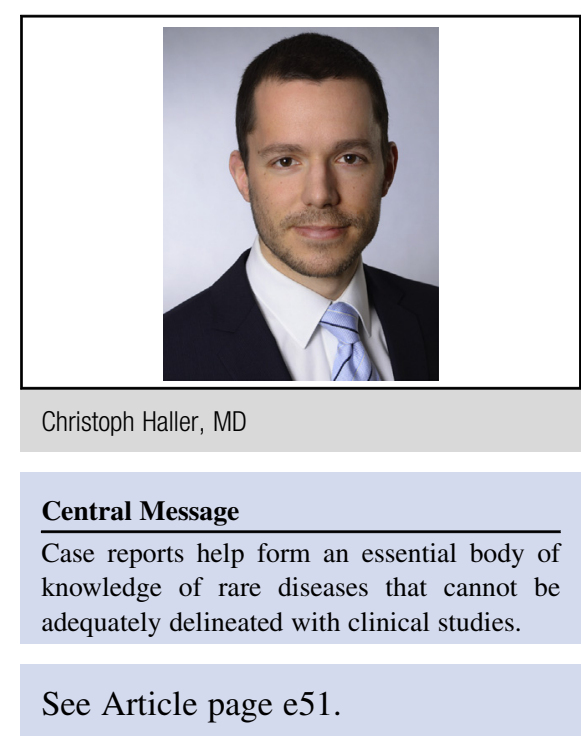

reasons that our specialty is as exciting as it is. Many case reports, however, have a common shortcoming: authors often do not appreciate that it is not only the pure existence of the disease that is worth publishing. It is much more valuable for the clinical community to describe the particular presentation, the assumptions made before diagnosis, the confirmation or reversal of the diagnosis, and the diagnostic tools used. It is essential to report the decision-making process, the therapeutic approach taken, and any difficulties encountered. Misdiagnoses, morbidity, and mortality are very educational. The reader needs to be able to relive the patient's course to benefit during clinical activity later on. Although not all the interesting information may be available in each case, the sharing of experience is the actual reason that case reports are an important and often underestimated tool, especially in rare diseases.

The report by Dellis and colleagues ${ }^{4}$ is highly appreciated, because it gives insight into the surgical management of patients with aorta-right atrial tunnel. It is a little unfortunate, though, that it falls short of the complexity of the case and its educational potential.

\section{References}

1. Türkay C, Gölbaşi I, Belgi A, Tepe S, Bayezid Ö. Aorta-right atrial tunnel. J Thorac Cardiovasc Surg. 2003;125:1058-60.

2. Gajjar T, Voleti C, Matta R, Iyer R, Dash PK, Desai N. Aorta-right atrial tunnel clinical presentation, diagnostic criteria, and surgical options. J Thorac Cardiovasc Surg. 2005;130:1287-92.

3. Lee S, Kim SW, Im SI, Yong HS, Choi CU, Lim HE, et al. Aorta-right atrial tunnel: is surgical correction mandatory? Circulation. 2016;133:e454-7.

4. Dellis SL, Pennel T, Said-Hartley Q, Zilla P. Sinus of Valsalva-right atrial tunnel causing heart failure in a 38-year-old. J Thorac Cardiovasc Surg. 2018;155:e51-3. 